\title{
A study on evaluation of biomedical waste management in a tertiary care hospital in South India
}

\author{
Ramalingam A. J. ${ }^{1}$, Saikumar C. ${ }^{2}$ \\ ${ }^{1}$ Dr. Aishwarya J Ramalingam, Assistant Professor, ${ }^{2}$ Dr. Chitralekha Saikumar, Professor, both authors are affiliated with \\ Department of Microbiology, Sree Balaji Medical College \& Hospital, Bharath Institute of Higher Education and \\ Research (BIHER), N0-7, CLC Works Road, Chennai, Tamil Nadu, India.
}

Corresponding Author: Dr. Aishwarya J Ramalingam, Assistant Professor, Department of Microbiology, Sree Balaji Medical College \& Hospital, Bharath Institute of Higher Education and Research (BIHER), N0-7, CLC Works Road, Chennai, India. E-mail: jhaish@rediffmail.com

\begin{abstract}
Introduction: Bio-Medical wastes are classified based on their source of generation which includes various risk factors relatedto their handling and final disposal. The segregation of waste at the source of generation is the significant step.The compliance in various categories of biomedical waste management in a tertiary care hospital was evaluated. Materials and Methods: A checklist containing 17 parameters related to biomedical waste management such as 'condition of waste containers', 'segregation of waste', 'mutilation of recyclable waste was prepared and observed for compliance in 25 different patient care areas such as 9 Operation theatres, 1 casualty, 11 wards and 4 ICU. Each area was visited on any 3 non-consecutive days in the study period of 6 months from August 2017 to January 2018. Thus, a total of 6 visits were made to each area and mean percentage scorewas analysed for each area and each category of biomedical waste management. Results: For OTs, the mean percentage for 'condition of waste containers', 'segregation of waste', 'mutilation of recyclable waste' was $90 \%, 97 \%$ and $93 \%$ respectively. In casualty, the mean percentage was $89 \%$, 94\% and $87 \%$ respectively. For wards, the meanpercentage for these categories was $88 \%, 93 \%$ and $89 \%$ respectively; and for ICUs, the meanpercentage was $88 \%, 100 \%$ and $92 \%$ respectively. Conclusion: It was determined that more importance needs to be rested for 'mutilation of recyclable waste' especially in wards.
\end{abstract}

Keywords: Bio-Medical Waste, Bio-medicalwaste segregation, Waste disposal, Biomedical waste management

\section{Introduction}

Biomedical waste (BMW) is defined as any waste generated when patient care activities are carried out in a health- care setting, which has the potential to cause harm to human beings and environment. It is also known as clinical waste, medical waste and health-care waste. It constitutes about 15 to $25 \%$ of total waste generated in a hospital [1]. In order to avoid harm to human beings, animals and the environment special precautions and treatment modalities are required for BMW [2]. Most common pathogens found to be transmitted by biomedical waste [3] are Human Immunodeficiency Virus (HIV), Hepatitis B Virus (HBV) and Hepatitis C Virus (HCV). It is therefore one of the top priorities for the Hospital management and the healthcare professional to implement a proper policy and to ensure that the waste management practices are being followed. Hence, due care is taken while handling and disposing it [1].

The World Health Organization (WHO) has classified medical waste into eight categories [1] which includes general waste, pathological, radioactive, chemical, infectious to potentially infectious waste, sharps, pharmaceuticals, pressurized containers as described in Table 1. Hospitals generate waste, which is growing over the years in its volume and type poses a threat to public health and environment in addition to the risk for patients and workers who handle them. The sources for biomedical waste management includes hospitals,primary health centres, research centres, blood banks, mortuaries, animal houses, slaughter houses, blood donation camps.

Manuscript received: $07^{\text {th }}$ November 2018

Reviewed: $16^{\text {th }}$ November 2018

Author Corrected: $23^{\text {th }}$ November 2018

Accepted for Publication: $30^{\text {th }}$ November 2018

Pathology Update: Tropical Journal of Pathology \& Microbiology Available online at: www.pathologyreview.in 518 | P a g e 


\section{Original Research Article}

Table-1: Classification of biomedical waste

\begin{tabular}{|l|l|l|}
\hline Category & Waste type & Treatment and disposal \\
\hline Category 1 & Human anatomical waste & Incineration and deep burial \\
\hline Category 2 & Animal waste & Incineration and deep burial \\
\hline Category 3 & Microbiology and biotechnology waste & Incineration/microwave/autoclaving \\
\hline Category 4 & Sharps & Disinfection/microwaving/autoclaving/shredding \\
\hline Category 5 & Discarded medicine and cytotoxic drugs & Incineration/landfill \\
\hline Category 6 & Contaminated solid waste & Incineration/microwave/autoclaving \\
\hline Category 7 & Solid waste (other than sharps) & Disinfection/microwaving/autoclaving/shredding \\
\hline Category 8 & Liquid waste & Disinfection and discharge in drains \\
\hline Category 9 & Incineration ash & Disposal in municipal landfill \\
\hline Category 10 & Chemical waste & $\begin{array}{l}\text { Disinfection and discharge in drains and secured } \\
\text { landfill for solid wastes }\end{array}$ \\
\hline
\end{tabular}

The major problem associated with biomedical waste includes non-compliance of Bio-medical waste regulation and disposal. Improper segregation, results in mixing of hospital wastes with general waste making the whole system hazardous. This in turn causesunpleasant odour, multiplication of insects and transmission of communicable diseases like typhoid, cholera, hepatitis and AIDS through contaminated syringes and needles.Scavengers in the hospital are at a greater risk of getting infections such as tetanus and HIV. The recycling of disposable syringes, needles and other medical devices without proper sterilization also contribute to transmission of blood-borne infections such as Hepatitis, HIV. It is therefore essential to manage hospital waste in a most safe and eco-friendly manner [4].

The problem of bio-medical waste disposal in the healthcare setting has become atopic of increasing concern, encouraging hospital administration to pursue new techniques of safe, systematic and cost-effective disposal of BMW. Biomedical waste treatment and disposal includes incineration, autoclaving, microwave irradiation, chemical disinfection.

\section{Need of biomedical waste management in hospitals} [5]

The various reasons inviting a great need of management of hospitals waste are:

- Injuries from sharps.

- Poor infection control activity leading to nosocomial infections in patients.

- Risk of infection outside hospital for scavengers handling BMW

- Risk of infection to public living in the vicinity of hospitals.
- Risk associated with harmful chemicals, drugs to persons handling wastes at all levels.

- "Disposable" being repacked and sold by immoral elements.

- Risk of environmental pollution such as air, water and soil directly due to waste, or due to defective incineration emissions and ash.

In India, the legislation governing Biomedical waste management is called as Bio-Medical Waste (Management and Handling) Rules, 1998 [6] and has been propagated under Environment (Protection) Act, $1986[7]$.

There are principally four functions for biomedical waste management at source of generation. They are placement of waste containers or bins lined with waste bags at source of generation, segregation of waste, mutilation of recyclable waste and disinfection of waste $[1,2]$.

The present study was conducted with the objective to evaluate biomedical waste management practices at source of generation in a tertiary care hospital of South India.

\section{Aims \& Objectives}

To evaluate the practices of biomedical waste management such as condition of waste receptacles, segregation of waste, mutilation of recyclable waste in different patient care areas in a tertiary care hospital in South India.The compliance in various categories of biomedical waste management in a tertiary care hospital was evaluated.

Pathology Update: Tropical Journal of Pathology \& Microbiology Available online at: www.pathologyreview.in 519 | P a g e 


\section{Materials and Methods}

Sample size: 25 different patient care areas such as 9 Operation theatres, 1 casualty, 11 wards and 4 ICU. Each area was visited on any 3 non-consecutive days in the study period of 6 monthsfrom August 2017 to January 2018. Areas were visited during morning hours between 7 am and 10 am and evening hours of the same day between $3 \mathrm{pm}$ and $5 \mathrm{pm}$ making a total of 6 visits to each area. All observations were made by same researcher. The chosen timings were such thatpatient's blood samples were withdrawn for lab diagnostic tests and maximum biomedical waste was generated in a patient care area. Due to practical difficulties in visiting the patient care areas during evening and night hours when the medications were given, such time period was excluded from the study.

Study design:A checklist was prepared containing the condition of waste containers, segregation of waste, mutilation of recyclable waste (Table 2)

\section{Condition of waste containers:}

- Is red colour bin available in each area?

- Is yellow colour bin available in each area?

- Is blue colour bin available in each area?

- Is green colour bin available in each area?

- Is red colour bag placed in the red colour bin in each area?

- Is yellow colour bag placed in the yellow colour bin in each area?

- Is blue colour bag placed in the blue colour bin in each area?

- Is green colour bag placed in the green colour bin in each area?

- Is the biohazard symbol printed over waste bags?

- Are the colour bins covered?

\section{Segregation of waste:}

- Does the red bin with red bag contain only plastics?

- Does the yellow bin with yellow bag contain only soiled infectious waste?

- Does the blue bin with blue bag contain only glass-broken or unbroken, metallic and body implants?

- Does the green bin with green bag contain general waste?

\section{Mutilation of recyclable waste:}

- Is used hypodermic needle destroyed?

- Is used hypodermic needle disposed in white puncture-proof containers?

- Is used hypodermic needle re-capped?

Each desirable observation was assigned ' 1 ' mark and each undesirable observation was assigned ' 0 ' mark. There were some parameters, observations which could be in part desirable and in part undesirable in a given area, such observation was assigned ' 0.5 ' mark. For example, if all the used hypodermic needles were destroyed and disposed in white puncture-proof container it is considered to be desirable and allotted " 1 " mark. If none of the used hypodermic needles were destroyed and disposed in white puncture-proof containers it is considered to be undesirable and allotted " 0 " mark. If some of the used hypodermic needles were destroyed and some were not destroyed it was allotted "0.5" mark.

In the finalscore-sheet, there were 10 parameters noted under category "condition of waste containers", 4 parameters were notedunder category "segregation of waste" and 3 parameters were notedunder category "mutilation of recyclable waste". Thus, a total of 17 parameters were observed in each study area. 


\section{Original Research Article}

Table-2: Sample checklist

\begin{tabular}{|c|c|c|c|}
\hline \multirow[t]{2}{*}{ S. No } & \multirow[t]{2}{*}{ Parameter } & \multicolumn{2}{|c|}{ Observation } \\
\hline & & Yes & No \\
\hline 1. & $\begin{array}{l}\text { Condition of waste containers: } \\
\text { - Is red colour bin available in each area? } \\
\text { - Is yellow colour bin available in each area? } \\
\text { - Is blue colour bin available in each area? } \\
\text { - Is green colour bin available in each area? } \\
\text { - Is red colour bag placed in the red colour bin in each area? } \\
\text { - Is yellow colour bag placed in the yellow colour bin in each area? } \\
\text { - Is blue colour bag placed in the blue colour bin in each area? } \\
\text { - Is green colour bag placed in the green colour bin in each area? } \\
\text { - Is the biohazard symbol printed over waste bags? } \\
\text { - Are the colour bins covered? }\end{array}$ & & \\
\hline 2. & $\begin{array}{l}\text { Segregation of waste: } \\
\text { - Does the red bin with red bag contain only plastics? } \\
\text { - Does the yellow bin with yellow bag contain only soiled infectious waste? } \\
\text { - Does the blue bin with blue bag contain only glass-broken or unbroken, } \\
\text { metallic and body implants? } \\
\text { - Does the green bin with green bag contain general waste? }\end{array}$ & & \\
\hline 3. & $\begin{array}{l}\text { Mutilation of recyclable waste: } \\
\text { - Is used hypodermic needle destroyed? } \\
\text { - Is used hypodermic needle disposed in white puncture-proof containers? } \\
\text { - Is used hypodermic needle re-capped? }\end{array}$ & & \\
\hline
\end{tabular}

Data analysis: The mean percentage score was calculated for all categories of biomedical waste management and for all the areas. In order to obtain the score for a particular biomedical waste management category, the marks attainedin 6 visitswas summated and the mean percentage score was calculated. The overall score of the particular category of biomedical waste management and overall score of a particular area were analysed. StatisticalPackage for Social Sciences (SPSS Inc., Chicago, IL, version 15.0 for Windows) was used for statistical analysis. All the quantitative variables were analysed using mean, median (measures of central location) and standard deviation, 95\% confidence interval (measures of dispersion).

\section{Results}

Analyzation \& interpretation of data: For OTs, the mean percentage score for 'condition of waste containers', 'segregation of waste', 'mutilation of recyclable waste' was $90 \%, 97 \%$ and $93 \%$ respectively. In casualty, the mean percentage score was $89 \%, 94 \%$ and $87 \%$ respectively. For wards, the mean percentage score for these categories was $88 \%, 93 \%$ and $89 \%$ respectively; and for ICUs, the mean percentage score was $88 \%, 100 \%$ and $92 \%$ respectively (Table 3).

Table-3: Results

\begin{tabular}{|l|c|c|c|c|c|}
\hline $\begin{array}{l}\text { Category of Biomedical } \\
\text { waste management }\end{array}$ & $\begin{array}{c}\text { OT(n=9) } \\
(\mathbf{\%})\end{array}$ & $\begin{array}{c}\text { Casualty } \\
(\mathbf{n = 1}) \\
(\mathbf{\%})\end{array}$ & $\begin{array}{c}\text { Wards } \\
(\mathbf{n = 1 1}) \\
\mathbf{( \% )}\end{array}$ & $\begin{array}{c}\text { ICU (n=4) } \\
(\mathbf{\%})\end{array}$ & $\begin{array}{c}\text { Overall score of } \\
\text { category of Biomedical } \\
\text { waste management } \\
(\mathbf{n = 2 5})(\mathbf{\%})\end{array}$ \\
\hline $\begin{array}{l}\text { Condition of waste } \\
\text { containers }\end{array}$ & 90 & 89 & 88 & 92 & 90 \\
\hline Segregation of waste & 97 & 94 & 93 & 100 & 96 \\
\hline $\begin{array}{l}\text { Mutilation of recyclable } \\
\text { wastes }\end{array}$ & 93 & 87 & 89 & 92 & 90 \\
\hline Overall score of the area(\%) & 93 & 90 & 90 & 95 & 92 \\
\hline
\end{tabular}




\section{Original Research Article}

\section{Discussion}

The current practice of poor biomedical waste management poses a huge threat to the community. There is risk of transmission of various communicable diseases such as gastro-intestinal infections, respiratory tract infections, skin diseases due to various modes of transmission such as injuries from sharps. Enterococcus species, Staphylococcus aureus, Escherichia coli, Klebsiella species, Pseudomonas species, Acinetobacter species Clostridium tetani, HIV, Hepatitis A, Hepatitis $\mathrm{B}$ are some of the most common microorganisms responsible for infections [8].

The assessment of scores of different areas showed that score related to condition of waste containers and segregation of waste was not significantly different among various areas such as OTs, casualty, various wards and ICUs.

The score related to 'mutilation of recyclable waste' was found to be considerably different between OTs and casualty. The score in OTs $(93 \%)$ was significantly higher than casualty (87\%).

Segregation of waste is the most essential step for proper management of BMW as waste segregated into various colour-coded containers is eventually taken to different sites for disposal. Presence of anincorrect kind of waste in a particular container will apparently nullify the efforts of appropriate disposal of waste. This implies that for proper segregation of waste, the waste bins in appropriate number, at appropriate places and with appropriate colour-code are necessary to be consigned at the source of generation of waste.

The mean percentagescore of condition of waste containers in all the patient care areas in this study was more than $80 \%$. Several studies have found poor condition of waste containers for waste disposal. In a study conducted in South India, there were only white bins for all types of Bio-medical waste for visual reasons making segregation practices difficult [9]. The high score of condition of waste containers in all patient care areas in present study indicates that the basic organisation for proper segregation of waste at the point of generation of waste was well in place in the hospital. However, it was found that most of the waste containers were open without any lid over them. Waste receptacles should be covered with foot-operated lids [1] and so it is necessary to progressively replace the prevailing open type waste containers with the ones having footoperated lids.

High score for 'segregation of waste' (96\%) shows that this fundamentalpart of waste management was being properlyattended. In a study in a tertiary care hospital in Mumbai [10], it was found that waste segregation was less than $40 \%$ which was unsatisfactory. In studies conducted in Egypt [11] and Ethiopia [12], the waste segregation practices were found to be poor. Other studies from Lucknow and Belgaum, India showed good waste segregation practices. However, the precise percentage of areas where segregation practices were found good were not documented by the authors.

As segregation of BMW is the most vital aspect of BMW management more focus needs to be rested in certain areas of hospital particularly in wards as the score $(93 \%)$ was relatively less as compared to other areas of hospital, though this difference was not statistically substantial. The high score in ICUs couldpossibly be due to relatively good staff to patient ratio compared to relatively less favourable staff to patient ratio may be the cause for relatively lower score in wards.

It was found that score of 'mutilation of recyclable waste' in casualty and wards were significantly lower as compared to OTs and Intensive care units. The relatively poor score in these areas indicates that care has to be taken to sensitise the interns and nurses regarding BMW segregation. Further analysis of 'mutilation of recyclable waste' showed that some health-care workersfailed to mutilate the used hypodermic needles prior to disposal in white punctureproof containers. It makes it vital to mutilate used recyclables right after use thus leaving no possibility for their illegal re-circulation and reuse [13]. Astudy from Pakistanshowed $60 \%$ compliance towards disposal of sharps [14]. A study from China showed 8.9 to $23.3 \%$ compliance towards disposal of sharps [15] as they were inappropriately disposed. These findings were very low compared to our study. In our country, currently there are about 198 common BMW treatment facility (CBMWTF) in operation and 28 under construction [16]. Hence, there is a great necessity for rapid development of many more CBMWTF to satisfy the requirements of BMW treatment and disposal [17].

Recommendations and follow-up: The following recommendations were made for the improvement of biomedical waste management practices of the hospital.

- Adequate training and proper use of personal safety equipment (PPE) should be offered to waste handling

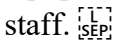

- Segregation of waste should start at the source of generation.

- Transportation of bags should be done separately and in closed trolleys. 


\section{Original Research Article}

- Periodic sensitisation of health-care workers and house-keeping staff should be done more consistently in order to emphasize on the importance of usage of personal protective equipment.

- Periodic surprise inspection of the biomedical waste generating areas by authorities and implementation of accountability for every personnel involved in biomedical waste management.

- Records onsource of waste generation, treatment, storage and disposal should be maintained by the hospital.

\section{Conclusions}

The present study was done to evaluate the compliance of biomedical waste management among different patient care areas in a tertiary care hospital in South India based on a checklist. It was found that more importance needs to be rested for 'mutilation of recyclable waste' especially in wards. Hospital administrators may need to devise and implement a plan for providing adequate and appropriate training to Health Care Workers (HCW) so as to tackle the deficiencies detected in the study. In order to protect our environment and public health we must sensitize ourselves to this important issue.

Input towards existing knowledge: Although the knowledge of biomedical waste management is adequate among the doctors and other health care workers, there was a deficit in practical implementation. Also, data about the knowledge and compliance was not adequate in the locality under study. Hence, this study was done to analyse the compliance of biomedical waste management in our hospital so as to create awareness about safe practices from the point of generation to final disposal. Recommendations and follow-up were made for the improvement of biomedical waste management practices of the hospital. This would lead to a clean and safe environment to live in.

Authors' contributions: Aishwarya J Ramalingam conceived, designed the study; collected data, performed data analysis; drafted the manuscript. Chitralekha Saikumar participated in data analysis and helped in drafting the manuscript.

Findings: Nil; Conflict of Interest: Non initiated. Permission from IRB: Yes

\section{References}

1. Pruss A, Cirouit E, Rushbrook P. Definition and Characterization of Health-Care Waste. $1^{\text {st }}$ ed. Safe
Management of Wastes From Health-Care Activities. Geneva: WHO; 1999: Chapter 2, Definition; p 2.

2. Manual on Solid Waste Management, Ministry of Urban Development, Government of India. Available from http://www.mohua.gov.in. Last accessed on $30 / 11 / 18$.

3. Collins $\mathrm{CH}$, Kennedy DA. Microbiological hazards of occupational needlestick and 'sharps' injuries. J ApplBacteriol. 1987 May;62(5):385-402.

4. Centre for environment education and technology. Bio-medical waste management - burgeoning issue; 2008.

5. Hem Chandra. Hospital waste- An Environmental Hazard and Its Management. Enviro news 1999; $5(3)$.

6. Bio-medical Waste (Management and Handling) Rules, 1998, Ministry of Environment and Forests, Government of India. Available fromhttp://hspcb.gov. in/BMW\%20Rules.pdf.Last accessed on 05/12/18.

7. The Environment (Protection) Act, 1986, Ministry of Environment and Forests, Govt. of India. Available from http://envfor.nic.in/legis/env/env1.html. Last accessed on $05 / 12 / 18$.

8. Blenkharn JI. The disposal of clinical wastes. J Hosp Infect. 1995 Jun;30 Suppl:514-20.

9. Blenkharn JI. Standards of clinical waste management in hospitals--a second look. Public Health. 2007 Jul;121 (7):540-5. Epub 2007 Feb 12. DOI:10.1016/j.puhe.2006.12.005.

10. Nataraj G, Baveja S, Kuyare S, et al. Report: Medical students for monitoring biomedical waste segregation practices--why and how? Experience from a medical college. DOI:10.1177/0734242X07081481.

11. Talaat M, Kandeel A, El-Shoubary W, et al. Occupational exposure to needlestick injuries and hepatitis B vaccination coverage among health care workers in Egypt. Am J Infect Control. 2003 Dec;31 (8): 469-74. DOI:10.1016/j.ajic.2003.03.003.

12. Debere $\mathrm{MK}$, Gelaye $\mathrm{KA}$, Alamdo $\mathrm{AG}$, et al. Assessment of the health care waste generation rates and its management system in hospitals of Addis Ababa, Ethiopia, 2011. BMC Public Health. 2013 Jan 12;13:28. doi: 10.1186/1471-2458-13-28. 


\section{Original Research Article}

13. Battersby A, Feilden R, Nelson C. Sterilizable syringes: excessive risk or cost-effective option? Bull World Health Organ 1999; 77(10):812-819. Sičpi

14. Janjua NZ. Injection practices and sharp waste disposal by general practitioners of Murree, Pakistan. J Pak Med Assoc. 2003 Mar;53(3):107-11.

15. Murakami H, Kobayashi M, Zhu X, et al. Risk of transmission of hepatitis $\mathrm{B}$ virus through childhood immunization in northwestern China. Soc Sci Med. 2003 Nov;57(10):1821-32.
16. Bio-Medical Waste Management Rules. 2016 Published in the Gazette of India, Extraordinary, Part II, Section 3, Sub-Section (i), Government of India Ministry of Environment, Forest and Climate Change. Notification; New Delhi 2016. Available from http://mpcb.gov.in/biomedical/pdf/BMW_Rules_2016. pdf. Last accessed on 05/12/18

17. Datta P, Mohi GK, Chander J. Biomedical waste management in India: Critical appraisal. J Lab Physicians. 2018 Jan-Mar;10(1):6-14. doi: 10.4103 /JLP.JLP_89_17.

\section{How to cite this article?}

Ramalingam A. J., Saikumar C. A study on evaluation of biomedical waste management in a tertiary care hospital in South India.Trop J Path Micro 2018;4(7):518-524.doi:10.17511/ jopm.2018.i07.07. 